Pre-print

Working paper posted prior to peer review, August 2019.

\title{
Future-orientation (as trait and state) promotes reputation-protective choice in moral dilemmas
}

\author{
Andrew Vonasch \\ University of Canterbury \\ Hallgeir Sjåstad \\ Centre for Applied Research at NHH - Norwegian School of Economics
}

\begin{abstract}
By neglecting the life-long importance of having a good reputation, humans can profit in the short run from immoral behavior. Thus, reputation-protection is an intertemporal choice. In three pre-registered studies $(N=1,492)$, we tested the hypothesis that future-orientation would increase people's willingness to protect their reputation from harm. In hypothetical scenarios, people had to choose whether they would pay an immediate cost to prevent a devastating rumor from spreading. Study 1 found that traitbased future-orientation was positively correlated with reputation-protection. Study 2 manipulated time perspective experimentally, and found that future-focus (vs. present-focus) had a positive and causal effect on reputation-protection. Study 3 was a high-powered replication, showing that the effect of future-focus on reputation-protective choice was robust, and mediated by reputational concern. In line with common advice around the world of protecting one's reputation from harm, one way people may achieve that goal is to think about the future before acting.
\end{abstract}

Keywords: reputation; morality; future thinking; intertemporal choice Word count: 4,677

\section{Author information:}

Both authors contributed equally to this paper. Correspondence concerning this research can be addressed to Andrew Vonasch (e-mail: andy.vonasch@gmail.com) or Hallgeir Sjåstad (e-mail: hallgeir.sjastad@snf.no).

\section{Open Science:}

In all three studies, the hypotheses and statistical analyses were pre-registered in advance of the data collection. In the event of publication, data and materials will be made openly available at OSF.

\section{Funding:}

This work was partially supported by the Research Council of Norway through its Centres of Excellence Scheme, FAIR project No 262675. 


\section{Introduction}

In Aesop's fable "the boy who cried wolf," a boy enjoys fooling the elderly with fake warnings of wolf attacks, but then no one believes him when he warns about a real attack. As a consequence, the whole village suffers for it as all their sheep are eaten by the wolf, and in one version of the fable the boy gets eaten too. A lesson one can derive from this story, is that your reputation is worth far more in the long run than any temporary pleasures you would gain while ruining it. Still, immediate pleasures are tempting, despite the long-term cost. This paper tests a psychological mechanism that enables people to safeguard their reputations: future thinking. Specifically, we will test the hypothesis that when people think about the future (by trait or state), they will be more willing to pay an immediate cost to protect their reputation from harm.

\section{Reputation as survival strategy}

Like Aesop, evolutionary theorists have long argued that reputation is among the most valuable traits people can cultivate (Trivers, 1971; Axelrod, 1984; Henrich \& Henrich, 2007; Tomasello, 2016). A good reputation enables cooperation with others, whereas a bad reputation destroys opportunities (Andreoni, 1988; Beersma \& Van Kleef, 2011; Wu, Balliet, \& Van Lange, 2016). Cultivating a good reputation reaps huge benefits: People satisfy nearly all of their needs through social relationships and cooperation with others (Baumeister, 2005; Nowak \& Highfield, 2011), and true self-sufficiency is incredibly rare. Both in modern societies and premodern tribes, people get most of their calories through cooperative efforts (Hill 2001; Alvard, 2012).

Moreover, a ruined reputation is dire. Until recently in history, being ostracized and excluded from the tribe meant near-certain death (Tomasello, 2016; Von Hippel, 2018). Therefore, people developed several mechanisms to protect their reputations. People intuitively protect it even when they act in anonymous choice settings (Jordan and Rand, 2019), and when they fail to protect it they feel guilt and shame (Gilbert, 1997; Tanaka et al. 2015). People also consciously recognize the importance of reputation. Corporations and wealthy people pay large sums of money to protect and repair their reputations (Ronson, 2016). Moreover, ordinary people prefer incurring serious costs including emotional discomfort and physical pain to a tarnished reputation-if the social damage is serious enough (Vonasch, Reynolds, Winegard, \& Baumeister, 2018).

Although people benefit by protecting their reputations, doing so costs lost opportunities for selfish or immoral actions in the present. For instance, criminals can often get away with stealing and scamming thousands of dollars before getting caught, which severely limits their future legitimate earnings (Pager, 2003). In the current investigation, we consider managing your reputation to be a form of intertemporal choice between immediate costs and (greater) rewards later. Just as people make trade-offs between short-term and long-term monetary rewards (Urminsky \& Zauberman, 2015), or between tasty but unhealthy snacks and healthy but less delicious foods, we suggest that people also make trade-offs between immediate immoral rewards and their long-term reputation. If so, people's time perspective may influence their reputationally-relevant decisions.

What psychological mechanisms enable people to sacrifice short-term gains to protect their reputation? Some intuitive, heuristic processes certainly help. People are disgusted and averse to even thinking about breaking taboos that could tarnish their reputation (Tetlock, 2003; Haidt, Rozin, McCauley, \& Imada, 1997). People also develop intuitions about cooperation - to reciprocate by default, and punish uncooperative people even at a cost to yourself (Rand, 2016). Thus, people might protect their reputation mainly by relying on heuristics or "mental rules of thumb" to behave morally as if someone is watching, even when people think they are not being observed (Jordan \& Rand, 2019). Based on such processes alone, it is fully possible that human reputation-protection resembles a form for "competence without comprehension" (Dennett, 2017), analogous to how squirrels have the 
competence to bury nuts in summer and dig them up in winter, without having any comprehension of why they are doing it or a conscious plan of their long-term future.

\section{Future-minded reputation?}

The present research, however, is concerned with a different possibility: Although reputational concern has an intuitive basis, conscious thinking about the future may amplify it further. Specifically, by focusing on the future, people might become more aware of the long-term value of maintaining a good reputation, and will therefore be more willing to make personal sacrifices to protect their reputation from harm. Whereas intuition tends to favor salient cues in the immediate choice situation (McClure, Laibson, Loewenstein, \& Cohen, 2004; Kahneman, 2011), conscious thought is useful in reshaping automatic behaviors to accommodate non-present information (Baumeister, Masicampo, \& Vohs, 2011). In particular, it enables the person to simulate the future as a collection of multiple possibilities, so that decisions in the present can be guided by anticipated outcomes (Baumeister, Maranges, \& Sjåstad, 2018). Thus, future-oriented thinking might be especially useful to prioritize the long-term benefits stemming from a good reputation, even when the immediate cost of protecting one's reputation is substantial.

In psychological research, future-orientation has been studied as both a stable trait and a situational state, and we predict that both forms will be positively associated with reputation-protective choice. Previous research has found that people who habitually consider the future consequences of their actions tend to achieve better outcomes in life (de Ridder et al., 2012; Strathman et al., 1994), and they tend to behave more pro-socially in resource dilemmas (Kortenkamp \& Moore, 2006). Nonetheless, recent studies have also showed that future-oriented thinking is also a malleable state that has causal effects on subsequent decision-making (Bulley, Henry, \& Suddendorf, 2016). For example, people induced to think about the future can become more generous in economic games and charity donation scenarios, when the choice situation is framed as public and observable to others (Sjåstad, 2019). Building and extending on this research, the central hypothesis in the current investigation is that future-orientation will motivate people to protect their moral reputation from harm, even when doing so requires a personal sacrifice in the present.

\section{Research overview}

Three pre-registered studies $(\mathrm{N}=1,492)$ tested the hypothesis that future-oriented thinking increases people's willingness to incur a personal cost to protect their reputation from harm.

Study 1 examined individual differences in future-orientation to determine whether people with an above-average propensity to think about the future are more willing to make reputation-protective choices than people who focus more on the present. Study $2(a, b, c)$ experimentally manipulated futureoriented thinking across three situations in which reputation damage were possible, testing the hypothesis that thinking about the future causes an increase in people's willingness to make personal sacrifices to protect their reputation. Study 3 was a high-powered and combined replication of the three experiments in Study 2. Crucially, Study 3 also tested the hypothesis that higher reputational concern would mediate the positive effect of future thinking on reputation-protective choice.

We report all of the relevant studies we have conducted testing this hypothesis, and all of the measures in each study. All three studies were pre-registered in advance of each data collection.

\section{Study 1}

Study 1 tested the correlation between future-orientation as an individual trait and preference, and the willingness to pay a personal cost to protect one's moral reputation. Dispositional futureorientation was measured with the 'consideration of future consequences'-scale, referring to the broad tendency to value and prioritize future rewards over present ones (Strathman et al., 1994), and a choice- 
based measure of monetary time preferences (Falk et al., 2016), which is more narrowly focused on the willingness to choose a larger payment in the future over a smaller payment in the present. To enable a broader and cross-situational outcome measure, the participants in Study 1 made a series of three hypothetical choices based on each of the three scenarios used in Study $2 a, 2 b$ and $2 c$. Thus, the desire to protect one's moral reputation was measured as the average number of reputation-protective decisions across three different decision scenarios.

The general hypothesis was that future-oriented individuals would tend to be more inclined to pay a personal cost to protect their reputation than present-oriented individuals. Specifically, we predicted that high trait-levels of (a) future-oriented "time preferences" and (b) general futureorientation (CFC) would be positively correlated with the desire to protect one's moral reputation.

\section{Method}

We recruited 500 participants from Amazon Mechanical Turk, in which 21 participants were excluded for not following the instructions. The final sample consisted of 479 participants ( 229 female), with a mean age of 37 . The hypotheses, method and statistical analysis were pre-registered in advance of the data collection: http://aspredicted.org/blind.php?x=tx7jq7.

Independent variables. We used two different measures of dispositional future-orientation as predictor variables in this correlational study. Time preferences was assessed with a 25 -item hypothetical choice measure (Falk et al., 2016), in which the participants made a series of choices between a small monetary reward now vs. a gradually increasing monetary reward in 12 months. The higher the number of larger-later choices being made (0-25), the higher level of future-oriented time preferences $(M=10.86, S D=8.44)$. General future-orientation was assessed with the 'consideration of future consequences' scale (Strathman et al., 1994), using a 14-item self-report measure on a 7-point rating scale (1=Not at all like you, 7=Very much like you). Sample items: "When I make a decision, I think about how it might affect me in the future"; "My behavior is generally influenced by future consequences"; "I only act to satisfy immediate concerns, figuring the future will take care of itself" (reversed). Based on an average of those 14 items (7 of them reversed), a composite score of general future-orientation was computed as our second predictor variable ( $M=4.74, S D=0.98$, Cronbach's $\alpha=.88)$. The higher average score, the higher general future-orientation.

Dependent variable. Derived from a previous study by Vonasch and colleagues (2017), the desire to protect one's moral reputation was be measured as the average number of reputationprotective decisions across three different decision scenarios: 1) Willingness to spend one year in jail rather than letting one's community know about a crime, 2) Willingness to pay $\$ 1000$ to prevent a false rumor to spread (stealing money from a charity for children with cancer), 3) Willingness to refrain from price gouging during a flood (not setting a higher price for bottled water during a flood).

Scenario 1 and 2 are dichotomous choices, where a reputation-protective choice was coded as 1 and the reputation-neglecting choice was coded as 0 . Scenario 3 is a gradual decision (setting price for water from $\$ 0-\$ 20$, with $\$ 2$ as the normal price). For this choice, any response at $\$ 2$ or below was coded as reputation-protective (1), and any price-gouging response above $\$ 2$ was coded as reputationneglecting (0). As the dependent variable, the three choice measures were combined into an index measure of reputation-protection, with 0 as the lowest possible value and 3 as the highest. This exact procedure was specified in the pre-registration in advance of the data collection.

\section{Results}

As predicted, individual future-orientation was positively associated with a tendency to make reputation-protective choices. However, this effect was only found for general future-orientation (CFC), not for future-orientation in the form of monetary time preferences. 
Specifically, a Pearson product-moment correlation only found a very weak and non-significant association between monetary time preferences and the number of reputation-protective choices $(r=$ $.054, N=432, p=.261$ ). For our second predictor variable, a similar test found a modest but highly significant association between general future-orientation and reputation-protection $(r=.158, N=479$, $p=.001$ ). Moreover, a non-registered follow-up analysis showed that this association between general future-orientation and reputation-protective choice remained practically unchanged when controlling for monetary time preferences in a bivariate correlation $(r=.140, N=479, p=.004)$, despite the fact that general future-orientation and monetary time preferences was positively correlated $(r=.237, p=$ $.001)$.

Thus, the results showed that a broad and domain-general tendency to focus on and prioritize future consequences is positively correlated with the choice of safeguarding one's moral reputation, whereas the more "narrow" tendency to value a larger monetary reward in the future over a smaller monetary reward in the present did not seem to have this type of effect.

\section{Study 2}

Study 2 ( $a, b$ and $c$ ) experimentally manipulated future-orientation to test whether thinking about the future has a causal effect on reputation-protective choice, testing a possible mechanism for our correlational finding from Study 1 . We hypothesized that people who think about the future are more likely to protect their moral reputation from harm than people who think about the present.

\section{Method}

\section{Study 2a: Jail time vs. criminal record}

The hypothesis, method and statistical analysis were pre-registered in advance of the data collection: http://aspredicted.org/blind.php?x=723ay9. We recruited 200 participants from Mechanical Turk, and 14 were excluded for not following the instructions, leaving a final sample of 186 (96 women). Prior to the choice measure which served as the dependent variable, the participants were randomly assigned to a present thinking or future thinking condition (Sjåstad, 2019).

Present thinking condition: Before participants in the present thinking condition made their choice, they read the following instruction on a separate screen: "When you respond to the next question in this survey, please think about the immediate benefits of the choice you make. That is, we want you to focus on what would be the best choice for you to make in the situation you are in right now."

Future thinking condition: Before participants in the future thinking condition made their choice, they read the following instruction on a separate screen: "When you respond to the next question in this survey, please think about the future benefits of the choice you make. That is, we want you to focus on what would be the best choice for you to make in the long run."

Dependent variable: Participants chose between two hypothetical punishments for committing a crime (Vonasch, et al., 2017). “Option A: You will spend one year in jail. Once you have completed your time in jail, you will no longer be considered a criminal by your community and will have no criminal record. Option B: You will spend no time in jail. However, you will have a criminal record for the rest of your life and everyone in your community will consider you to be a criminal." At the end, participants also reported their age and gender.

\section{Results}

In line with the hypothesis, participants in the future thinking condition (78\%) were more likely than participants in the present thinking condition (57\%) to choose the jail sentence instead of reputation damage, $\chi^{2}(1, N=186)=9.16, p=.002, \phi=.22$. (We preregistered using $t$-tests to compare 
conditions in Study 2a, 2b, and 2c, but instead report chi-squared analyses when appropriate; nonetheless, the statistical test used does not influence the significance levels).

\section{Method}

\section{Study 2b: Pay $\$ 1000$ vs. reputation for stealing}

The procedure was identical to Study $2 \mathrm{a}$, with a new dependent variable. Participants imagined being wrongfully accused of stealing money from a cancer charity, and chose whether to pay a \$1000 fine to make the accusations anonymous. The hypothesis, method and statistical analysis were preregistered in advance of the data collection: http://aspredicted.org/blind.php?x=xp9h9f. We recruited 200 (new) participants from Mechanical Turk, and five were excluded for not following the instructions. The final sample consisted of 195 participants (108 men, 85 women, 2 other). As in Study 2a, participants were randomly assigned to the present thinking or future thinking conditions.

Dependent variable: Participants read this vignette: "Imagine you have been wrongfully accused for stealing money from a charity organization that works to cure cancer. Please choose which of the following punishments you would prefer if you had to choose. Option A: You will pay a $\$ 1000$ fine, which will guarantee $100 \%$ anonymity. No one will ever get to know about the false accusation. Option B: You will pay no fine. However, the rumor will spread and many people will believe it regardless of what you say."

\section{Results}

In line with the hypothesis, participants in the future thinking condition (60\%) were more likely to pay the fine (hush money) than participants in the present thinking condition $(44 \%), \chi^{2}(1, N=195)=$ $5.49, p=.019, \phi=.17$.

\section{Method}

\section{Study 2c: Lose profits vs. reputation for price gouging}

The procedure was identical to Study $2 a$ and $2 b$, with a new dependent variable. Participants chose whether to gouge customers by raising prices during a natural disaster. The hypothesis, method and statistical analysis were pre-registered in advance of the data collection:

http://aspredicted.org/blind.php?x=gu3fe7. We recruited 200 (new) participants from Mechanical Turk, in which 14 participants were excluded for not following the instructions. Thus, the final sample was 186 participants ( 90 women). The participants were randomly assigned to the present thinking or future thinking conditions.

Dependent variable: Before making their choice, participants read the following vignette: "Imagine you own a gas station in a small town where everybody knows everybody. A major flood is about to hit your area, and water is in high demand. Your gas station normally sells large bottles of water for $\$ 2.00$ each. You just received a large shipment of water bottles and expect to be able to sell as many as you like for any price below $\$ 20$ a bottle. During the flood, what price will you set for water?"

Participants then briefly explained why they set that price, and provided demographics.

\section{Results}

In line with the hypothesis, participants in the future thinking condition $(M=\$ 2.93, S D=3.36)$ charged lower prices than participants in the present thinking condition $(M=4.30, S D=4.81), t(186)=$ $2.20, p=.029, d=.32,(95 \% \mathrm{Cl}: 0.14,2.59)$. We also compared the percentage of participants who price gouged by condition. Price gouging was defined as setting any price above $\$ 2.00$. As predicted, fewer participants in the future thinking condition (30\%) gouged the price than in the present thinking condition (44\%), $\chi^{2}(1, N=188)=3.70, p=.055, \phi=.14$, although the difference was not significant. 
As an exploratory measure, we coded participants' explanations of why they chose the price they set. Specifically, two research assistants coded the responses as referencing reputation or not $(\alpha=$ $.95)$ and discussed responses until they fully agreed on coding. Consistent with the idea that futureorientation causes increased concern with reputation protection, participants in the future thinking condition (39\%) were more likely to mention reputation protection than participants in the present thinking condition (9\%), $\chi^{2}(1, N=188)=24.4, p<.001, \phi=.36$. Participants who reported being concerned about their reputation also set lower average prices $(M=2.30, S D=1.57)$ than participants who did not mention concern $(M=4.09, S D=4.69), t(186)=2.40, p=.018,(95 \% \mathrm{Cl}: .32,3.26)$, and were less likely to gouge the price ( $22 \%$ vs. $42 \%), \chi^{2}(1, N=188)=5.58, p=.018, \phi=.17$.

\section{Study 3}

Study 3 was a high-powered and combined replication of the three experiments in Study 2 ( $a, b$ and c). Inspired by the "small telescopes" approach (Simonsohn, 2015) and recent calls for large-scale internal replications in psychological research, the recruited sample was 2.5 times larger per cell as in the original studies. As the outcome measure, we used an average score of the three decision scenarios used in Study 1 and Study 2. In sum, this enabled a broader and more robust test of whether futureorientation promotes reputation-protection.

Crucially, Study 3 also measured reputational concern as a potential mediator variable. The central hypothesis was that the future-minded tendency to make personal sacrifices to protect one's reputation would replicate, and that this effect would be driven by elevated reputational concern.

\section{Method}

The hypotheses, method and statistical analysis of Study 3 were pre-registered in advance of the data collection at: http://aspredicted.org/blind.php?x=vr8c7z. We recruited 500 participants from Mechanical Turk, and 54 were excluded for not following the instructions. The final sample was 446 participants ( 90 female). According to a sensitivity analysis in the $G^{*}$ power software, the final sample provided $90 \%$ power to detect a true effect of $d=.31$ or larger ( $p<.05$, two-tailed). The average effect size of the three experiments in Study 2 was $d=.36$, which suggests that Study 3 had high statistical power to detect a similar effect.

The experimental manipulation of time perspective was identical to Study 2, and the dependent variable was identical to Study 1 (i.e., a combination of all three decision scenarios used in experiments $2 a, 2 b$ and $2 c$ ). Participants were randomly assigned to the present thinking or future thinking condition, and then made three hypothetical choices in different moral dilemmas: a: jail scenario; b: charity stealing scenario; c: price gouging scenario (presented in counter-balanced order). In each decision scenario, the reputation-protective choice was coded as 1, and the reputation-neglecting choice was coded as 0 . As in Study 1 , the specific dependent variable was therefore the average number of reputation-protective choices across the three scenarios (0-3).

As a novel addition in Study 3, participants responded to a four-item measure of reputational concern immediately after their decision in each scenario (Beersma \& Van Kleef, 2011; Wu, Balliet, \& Van Lange, 2016; Sjåstad, 2019). "Based on the choice you just made, please indicate to what degree you agree with each statement below" (1=totally disagree, 7=totally agree): "When making my choice, I thought about how others would think about me in the future"; "When making my choice, I wanted to avoid having other people think badly of me"; "When I made my choice, I wanted to make sure that others would evaluate me positively"; "I did NOT consider what people would say about me during the choice task" (reversed scored). In line with previous studies using this measure, the scale was reliable (Cronbach's $\alpha=0.92$ ).

As an extended replication of Study 2, the theoretical prediction was that focusing on the future should activate a greater concern for maintaining a positive reputation, and that such an elevated 
concern should increase people's willingness to make personal sacrifices to protect their reputation from harm.

\section{Results}

Future thinking and reputation-protective choice. As predicted, participants in the future thinking condition made a higher number of reputation-protective choices across the three decision scenarios $(M=1.88, S D=0.83, S E=0.05)$ than participants in the present thinking condition $(M=1.44$, $S D=0.98, S E=0.07), t(446)=5.09, p<.001, d=0.49(95 \% \mathrm{Cl}: 0.27,0.61)$. Specifically, participants in the future condition made a reputation-protective choice $63 \%$ of the time, whereas participants in the present thinking condition only made a reputation-protective choice $48 \%$ of the time. Thus, participants who focused on the future made a reputation-protective choice $15 \%$ more often than participants who focused on the present (see figure 1).

For future reference, we note that a non-registered follow-up analysis showed that the effect was consistently strong and highly significant for the first two scenarios from Study 2 (jail time: $p<.001$, cancer charity: $p<.001$ ), whereas there was no significant effect on the third scenario (price gouging: $p=.42$ ). Thus, the broad and pre-registered hypothesis of future-focused reputation-protection was supported, but when narrowing down the analysis to each specific scenario, the effect appears to be driven by a future-focused effect on two out of the three decision scenarios.

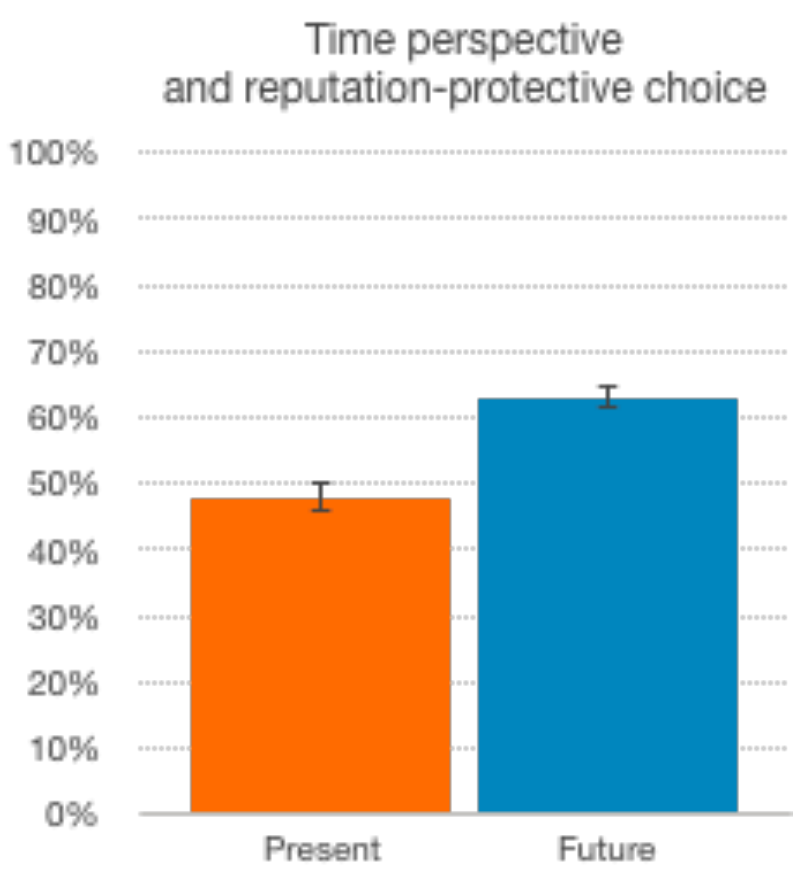

Figure 1: Study $3(\mathrm{~N}=446)$. The bar chart illustrates the average percentage of reputation-protective choices in the present condition and the future condition, across three different decision scenarios. Error bars indicate standard error. Participants who focused on the future (vs. the present) were significantly more willing to incur a personal cost to protect their moral reputation from harm $(+15 \%, d=.49, p<.001)$.

Mediation analysis. To test the pre-registered process hypothesis, we conducted a statistical mediation analysis with future-focus (vs. present-focus) as the independent variable, reputational concern as the mediator variable, and reputation-protective choice as the dependent variable. This analysis was conducted using the PROCESS macro in SPSS. 
As predicted, the results showed that the positive effect of future-focus on reputationprotective choice was mediated by reputational concern $(a b=0.55)$, as a bias-corrected confidence interval based on 10,000 bootstrap samples did not include the value $0(\mathrm{Cl}=0.43,0.68)$. Specifically, thinking about the future led to higher levels of reputational concern $\left(M_{\text {future }}=5.29, S D=1.31 \mathrm{vs}\right.$. $M_{\text {present }}$ $=3.63, S D=1.68 ; d=1.11, a=1.66, p<.001)$, and higher reputational concern was associated with a greater number of reputation-protective choices $(b=0.33, p<.001)$. When reputational concern was included as a mediator variable in the model, the direct effect of future-focus was no longer statistically significant $\left(c^{\prime}=0.12, p=0.157\right)$. These results suggest that a large proportion of the positive effect of future-focus on reputation-protective choice can be explained by a corresponding increase in the social concern for one's reputation.

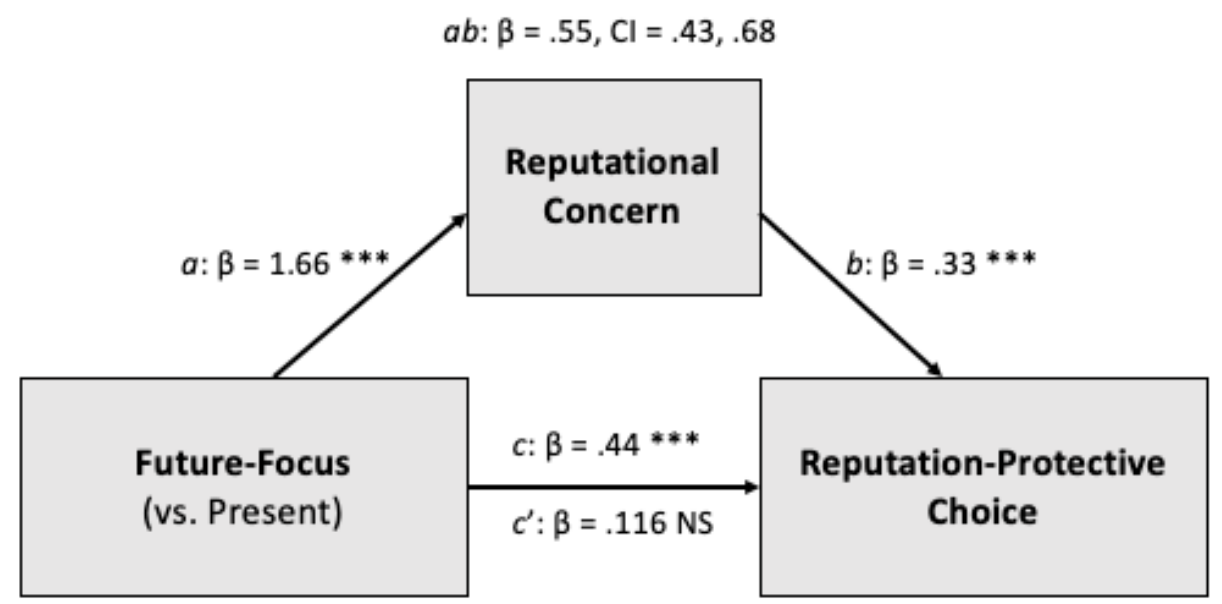

Figure 2: Study 3 ( $N=446)$. Participants who focused on the future (vs. the present) expressed stronger concern for their reputation, and this effect mediated the greater willingness to incur personal costs to protect their reputation from harm in specific choice scenarios $(\mathrm{Cl}=0.43,0.68)$.

\section{General Discussion}

Across three pre-registered studies and 1,492 participants, using both correlational and experimental designs, people who focused on the future were more willing to make a personal sacrifice to protect their moral reputation from harm. The results generalized to different choice scenarios in which participants had to decide whether they would pay an immediate cost (money or going to jail) to prevent a devasting rumor to spread in their social network. In a final high-powered replication experiment, participants who focused on the future were $15 \%$ more likely to make a reputationprotective choice than participants who focused on the present. A mediation analysis confirmed that future-focused thinking promoted reputation-protective choice by intensifying self-reported reputational concern.

Implications. In our view, securing a good reputation involves an intertemporal trade-off between present versus future benefits. As a good reputation is extremely valuable in social life, shortsighted thinking may put people at risk for neglecting the reputational consequences of their choices.

The results further support the idea that a central function of future-oriented thinking is to support pro-social behavior and cooperation (Sjåstad, 2019). In general, protecting one's reputation is an important reason for why people tend to act in line with social norms for honesty, generosity and moral concern for others (Tomasello, 2016; Trivers, 1971)-and actively thinking about the future seems to intensify this concern further. 
Limitations and future directions. Like much research on the psychology of judgment and decision-making, the outcome measures in the present investigation were based on non-incentivized choices in hypothetical scenarios. This enabled a range of study questions that would be impractical and perhaps unethical to study in a real-life context. Moreover, several studies suggest that hypothetical choices can be a "good enough" proxy for incentivized decisions in many cases, such as temporal discounting (Johnson \& Bickel, 2002) and generosity (Ben-Ner, Kramer, \& Levy, 2008). However, as there are also psychological differences between hypothetical and real choice (Camerer \& Mobbs, 2016), we acknowledge that it is an open question to what extent the present findings would generalize to real-life situations with actual consequences to the decision-maker.

Another limitation is that the participants were Americans recruited from the online labor platform of Amazon's Mechanical Turk ("Mturk"). Although the participant pool at Mturk is more diverse than university students (Buhrmester, Kwang, \& Gosling, 2011), which was previously the most common sample in psychological research, generalization of the present findings to different countries and cultural settings should be done with caution, and ideally, studied empirically in future research.

Future directions. Humans are extremely future-oriented compared to other animals, but people also tend to favor the present over the future (Suddendorf, 2013; Von Hippel, 2018). Just as different people have different discount rates for money and food, they might also discount the future benefits stemming from a good reputation in different ways. For individuals and groups who tend to focus on the future when important decisions are made, better reputation management might be part of the explanation for their long-term success.

\section{References}

Alvard, M. (2012). Human social ecology. The Evolution of Primate Societies, 141-162.

Andreoni, J. (1988). Why free ride?: Strategies and learning in public goods experiments. Journal of Public Economics, 37(3), 291-304.

Axelrod, R. (1984). The evolution of cooperation (Vol. 5145). Basic Books (AZ).

Baumeister, R. F. (2005). The cultural animal: Human nature, meaning, and social life. Oxford University Press.

Baumeister, R. F., Maranges, H. M., \& Sjåstad, H. (2018). Consciousness of the future as a matrix of maybe: Pragmatic prospection and the simulation of alternative possibilities. Psychology of Consciousness: Theory, Research, and Practice, 5(3), 223.

Baumeister, R. F., Masicampo, E. J., \& Vohs, K. D. (2011). Do conscious thoughts cause behavior? Annual Review of Psychology, 62, 331-361.

Beersma, B., \& Van Kleef, G. A. (2011). How the grapevine keeps you in line: Gossip increases contributions to the group. Social Psychological and Personality Science, 2(6), 642-649.

Ben-Ner, A., Kramer, A., \& Levy, O. (2008). Economic and hypothetical dictator game experiments: Incentive effects at the individual level. The Journal of Socio-Economics, 37(5), 1775-1784.

Bulley, A., Henry, J., \& Suddendorf, T. (2016). Prospection and the present moment: The role of episodic foresight in intertemporal choices between immediate and delayed rewards. Review of General Psychology, 20(1), 29-47. 
Buhrmester, M., Kwang, T., \& Gosling, S. D. (2011). Amazon's Mechanical Turk: A new source of inexpensive, yet high-quality, data? Perspectives on Psychological Science, 6(1), 3-5.

Camerer, C., \& Mobbs, D. (2016). Differences in behavior and brain activity during hypothetical and real choices. Trends in Cognitive Sciences.

Dennett, D. C. (2017). From bacteria to Bach and back: The evolution of minds. WW Norton \& Company.

De Ridder, D. T., Lensvelt-Mulders, G., Finkenauer, C., Stock, F. M., Baumeister, R. F. (2012). Taking stock of self-control: A meta-analysis of how trait self-control relates to a wide range of behaviors. Personality and Social Psychology Review, 16(1), 76-99.

Falk, A., Becker, A., Dohmen, T. J., Huffman, D., \& Sunde, U. (2016). The preference survey module: A validated instrument for measuring risk, time, and social preferences. IZA Discussion Papers, No. 9674.

Gilbert, P. (1997). The evolution of social attractiveness and its role in shame, humiliation, guilt and therapy. British Journal of Medical Psychology, 70(2), 113-147.

Haidt, J., Rozin, P., McCauley, C., \& Imada, S. (1997). Body, psyche, and culture: The relationship between disgust and morality. Psychology and Developing Societies, 9(1), 107-131.

Henrich, N., \& Henrich, J. P. (2007). Why humans cooperate: A cultural and evolutionary explanation. Oxford University Press.

Hill, K. (2002). Cooperative food acquisition by Ache foragers. Human Nature, 13(1), 105-128.

Johnson, M. W., \& Bickel, W. K. (2002). Within-subject comparison of real and hypothetical money rewards in delay discounting. Journal of the Experimental Analysis of Behavior, 77(2), 129-146.

Joireman, J., Shaffer, M. J., Balliet, D., \& Strathman, A. (2012). Promotion orientation explains why future- oriented people exercise and eat healthy: Evidence from the two-factor consideration of future consequences-14 scale. Personality and Social Psychology Bulletin, 38(10), 1272-1287.

Jordan, J.J. \& Rand, D.G. (2019). Signaling when nobody is watching: A reputation heuristics account of outrage and punishment in one-shot anonymous interactions. Forthcoming at Journal of Personality and Social Psychology.

Kahneman, D. (2011). Thinking, fast and slow. Macmillan.

Kortenkamp, K. V., \& Moore, C. F. (2006). Time, uncertainty, and individual differences in decisions to cooperate in resource dilemmas. Personality and Social Psychology Bulletin, 32(5), 603-615.

McClure, S. M., Laibson, D. I., Loewenstein, G., \& Cohen, J. D. (2004). Separate neural systems value immediate and delayed monetary rewards. Science, 306(5695), 503-507.

Nowak, M., \& Highfield, R. (2011). Supercooperators: Altruism, evolution, and why we need each other to succeed. Simon and Schuster.

Pager, D. (2003). The mark of a criminal record. American Journal of Sociology, 108, 937-975.

Rand, D. G. (2016). Cooperation, fast and slow: Meta-analytic evidence for a theory of social heuristics and selfinterested deliberation. Psychological Science, 27(9), 1192-1206. 
Ronson, J. (2016). So you've been publicly shamed. Riverhead Books.

Simonsohn, U. (2015). Small telescopes: Detectability and the evaluation of replication results. Psychological science, 26(5), 559-569.

Sjåstad, H. (2019). Short-sighted greed? Focusing on the future promotes reputation-based generosity. Judgment \& Decision Making, 14(2).

Suddendorf, T. (2013). The gap: The science of what separates us from other animals. Basic Books.

Strathman, A., Gleicher, F., Boninger, D. S., \& Edwards, C. S. (1994). The consideration of future consequences: Weighing immediate and distant outcomes of behavior. Journal of personality and social psychology, 66(4), 742.

Tanaka, H., Yagi, A., Komiya, A., Mifune, N., \& Ohtsubo, Y. (2015). Shame-prone people are more likely to punish themselves: A test of the reputation-maintenance explanation for self-punishment. Evolutionary Behavioral Sciences, 9(1), 1.

Tetlock, P. E. (2003). Thinking the unthinkable: Sacred values and taboo cognitions. Trends in cognitive sciences, 7(7), 320-324.

Tomasello, M. (2016). A natural history of human morality. Harvard University Press.

Trivers, R. L. (1971). The evolution of reciprocal altruism. The Quarterly review of biology, 46(1), 35-57.

Urminsky, O., \& Zauberman, G. (2015). The psychology of intertemporal preferences. The Wiley Blackwell handbook of judgment and decision making, 2, 141-181.

Vonasch, A. J., Reynolds, T., Winegard, B. M., \& Baumeister, R. F. (2018). Death before dishonor: Incurring costs to protect moral reputation. Social Psychological and Personality Science, 9(5), 604-613.

Von Hippel, W. (2018). The Social Leap: The New Evolutionary Science of who We Are, where We Come From, and what Makes Us Happy. Harper Collins.

Wu, J., Balliet, D., \& Van Lange, P. A. (2016). Reputation management: Why and how gossip enhances generosity. Evolution and Human Behavior, 37(3), 193-201. 